\title{
Greetings From Charter Member E. William Anderson
}

$\mathrm{F}$ rom the early days prior to World War II where dedicated young professionals attempted to bring order out of chaos; to the dark, dreadful days of the war; to the heady postwar days when great progress toward ecologically based management began to take strong root; to the present age where information exchange, gender equality, and environmental concern are household words; it has been a great ride!

My advice to those who are privileged to guide the ship as we continue into the 21 st Century-remember what is important: family, friends, land, and the people who are tied to the land.

Welcome to Spokane and the SRM's 2012 Annual Meeting!

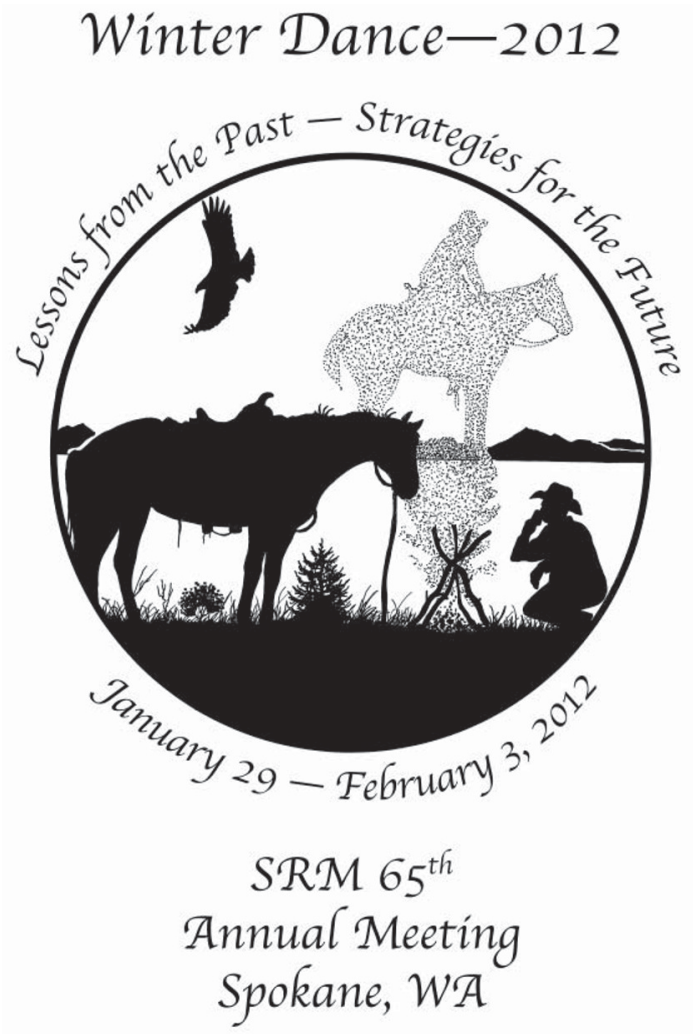

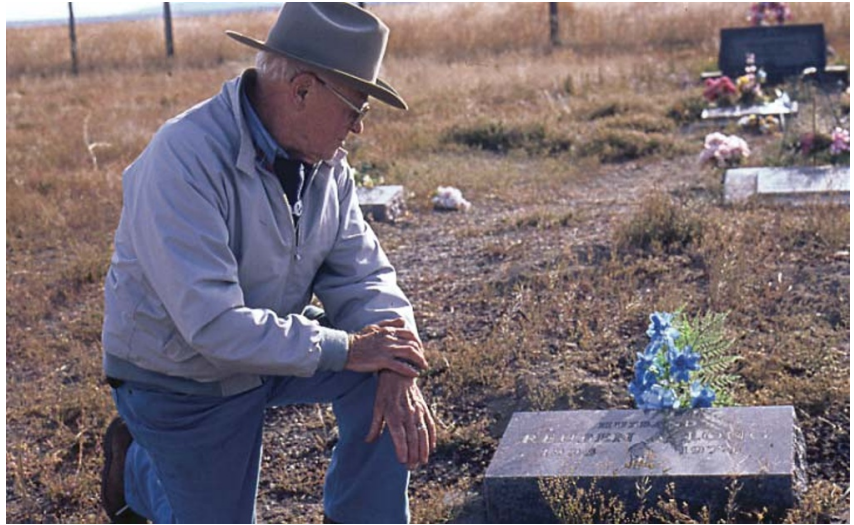

E. William Anderson is a charter member of the SRM, a former President of both the Pacific Northwest (PNW) Section and the Parent Society. $\mathrm{He}$ has received the highest honors the Section and Parent Society bestow, the Trail Boss Award and the Renner Award, respectively. He is the primary author of the SCS (now NRCS) ecological site guides for the State of Oregon and he is the Father of Coordinated Resource Management Planning (CRMP). Mr. Anderson received his education in Idaho and Oregon and served four years overseas in the Navy Air Corps during WWII. Since his birth 96 years ago, he has been active and engaged. In this photo, Mr. Anderson is shown in a contemplative moment at the grave of his colleague, Reub Long. Mr. Long was an author, cowboy philosopher, and supporter of rangeland management.

Editor's Note: As this issue was going to press, Rangelands learned that Mr. Anderson died peacefully on 3 March 2011 at the age of 96 . 